\title{
LOSS MODEL FOR OFF-DESIGN PERFORMANCE ANALYSIS OF RADIAL TURBINES WITH PIVOTING-VANE, VAR ABLE-AREA STATORS
}

Peter L. Meitner

Propulsion Laboratory

AVRADCOM Research and Technology Laboracories

Lewis Research Center

isnd

Arthur J. Glassman

Lewis Research Center

Cleveland, Ohio

Prepared for the

Aerospace Congress

sponsored by the Society of Automotive Engineers

Los Angeles, California, October 13-16, 1980

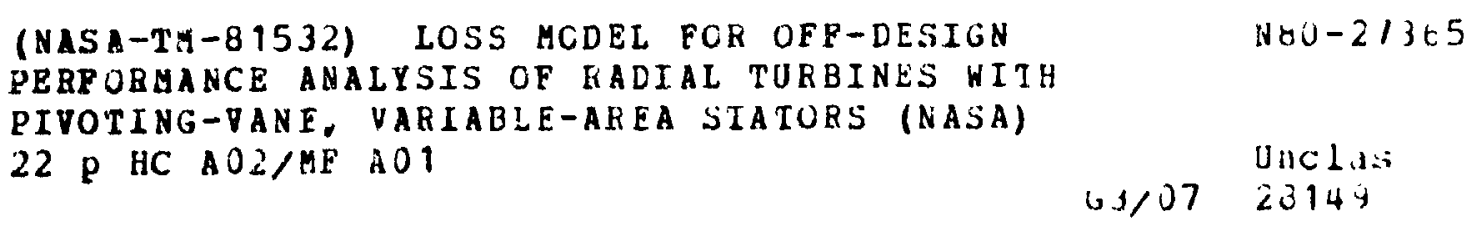

Nov-21365

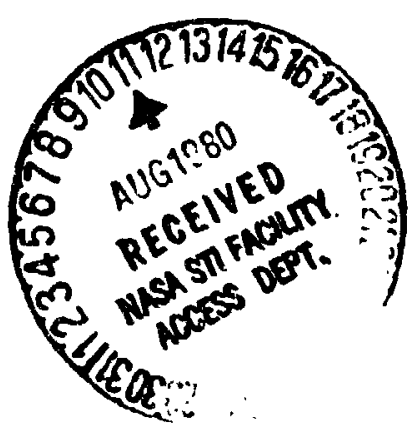

\section{NMSA}


LOSS MODEL. FOR OFF-DESIGN PERFORMANCE

ANALYSIS OF RADIAL TURBINES WITH

PIVOTING-VANE, VARIABLE-AREA STATORS

by Peter L. Meitner Propulsion Laboratory AVRADCOM Research and

Technology Laboratories

Lew is Research Center

ano

Arthur J. Glassman

Lewis Research Center

Cleveland, onio 


\section{ABSTRACT}

An off-design performance loss model is developed for variable-area (pivoted vane) radial turbines. The variation in stator loss with stator area is determined by a viscous loss model while the variation in rotor loss due to stator area variation (for no stator end-clearance gap) is determined through analytical matching of experimental data. An incidence loss model is also baseo on matching of the experimental data. A stator vane end-clearance leakage model is developed and sample calculations are made to show the predicted effects of stator vane end-clearance leakage on performance. 
FOR AUTOMOTIVE OR HELICOPTER APPLICATIONS gas turbine engine must operate over a wiot range of power settings. Conventional engine throttling (part power operation) is achieved by reducing engine speed, and therefore cycle pressure ratio, and temperature, which reduces overall thermal effi.ciency. To reduce engine thermal efficiency loss at part puwer, it is desirable to maintain constant engine speed, pressure ratio and temperature, while throttling with internal area changes to reduce flow, and thus power. A radial turbine with variable area stators can be operated in this manner over a broad flow range, $a$ ' $d$ if high turbine efficiency can be main ained, it can contribute significantly 10 high engine performance at part power. However, the effect of stator area variation and stator endclearance leakage on turbine performance must be known for proper engine performance prediction.

This paper presents a loss mudel for the off-design performance prediction of radial turbines with pivoted vane, variablearea stators. The mode $i$ is based on a previous loss model $(1)$ * which considers stator, incioence, and rotor losses, but which does not consider the ir variations with stator area changes. In the loss model presented herein, the effect of stator area variation on stator loss is accounted for by a viscous loss model, while the effects on rotor loss (for no stator end-clearance gap) are obtained by analytical matching of experimenta! data. The experimental dica is also used to obtain a revised incidence loss model. Finally, a clearance flow model is proposed to account for the effects of stator valle end-clearance leakage. Sample calculations are made to show the predicted effects of stator end-clearance leakage on performance for this model.

\section{SYMBOLS}

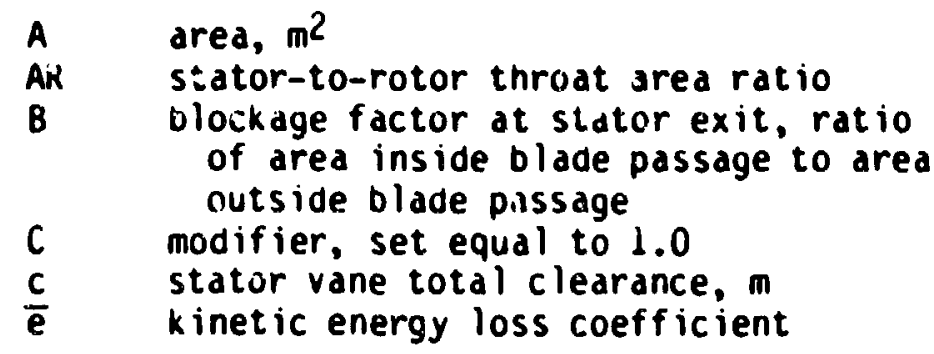

Meitner

*Numbers in parentheses designate References at eno of paper. 

shroud, $m$ incidence angle, degrees (defined by Eq. $(1 ?)$ )

$k$ rotor loss coefficient

L kinetic energy loss, J/kg

1 surface length, m

$n$ incidence exponent

PR stator total-pressure ratio (defined by Eq. (2))

$P$ absolute iressure, $N / \pi^{2}$

Q volume flow rate, $\mathrm{m}^{3} / \mathrm{sec}$ or critical velocity ratio function (defined by Eq. (7))

$r$ radius, $m$

Re Reynolds number based on stator vane chord

$s$ blade spacing it blade row exit, $m$

trailing edge tnickness, $m$

$v$ absolute iclocity, $\mathrm{m} / \mathrm{s}$

$H$ relative velocity, $\mathrm{m} / \mathrm{s}$

$w$ mass flow rate, $\mathrm{kg} / \mathrm{s}$

a fluid absolute flo'n angle measured from radial direction at stations $0,1, c$, and 3 and from axial direction at stations 4 and 5 , deg

B fluia relative flow angle measured from radial direction at stations $0,1, i$, and 3 and from axial direction at stations 4 and 5 , deg

$r$ ratio of specific heats
momentum thickness, $m$
density, $\mathrm{kg} / \mathrm{m}^{3}$

\section{Subscripts:}

$\begin{array}{ll}C & \text { clearance } \\ \text { IN } & \text { incidence } \\ \text { opt } & \text { optimum } \\ p & \text { main passage } \\ R & \text { rotor } \\ r & \text { radial component } \\ \text { ref } & \text { reference } \\ t & \text { total } \\ u & \text { tangential component } \\ 0 & \text { station at tirbine inlet } \\ 1 & \text { station immediately upstream of stator } \\ 2 & \text { exit } \\ 20 & \text { station immediately downstream of } \\ 3 & \text { stator exit } \\ 30 & \text { three-dimensional } \\ 4 & \text { station immediately upstream of rotor } \\ & \text { exit }\end{array}$

Me itner 
LOSS MOOEL

Figure 1 shows a cross-section of a iypicai radiai turoine and indicates the flow stations pert inent to the loss wodel description. The loss model presented herein is based on the loss model of (1), in which radial turbine performance is modeled by stator, rotor and incidence losses. This model is modified to account for the effects of stator area variation, and vane enoclearance leakage. In addition, the incidence loss model is changed for better agreerent with test data.

STATOR LOSS - The stator loss model considers the vane passage flow, the clearance flow, and the mixing process, which also includes the sudden increase in flow area at the trailing edge.

Passage Flow - The stator passage region is defined as the region between the vanes and extending the height $(h-c)$ of the vanes. Since the vane exit angle can be assumed from the turbine geometry, the vane passage flow rate is

$$
w_{p}=2 a r_{1}(n-c) B_{p_{1}} v_{1} \cos a_{1, p}
$$

The stator passage loss from station 0 to 1 is represented by a total pressure ratio PR where

$$
P R=\frac{p_{1, t}}{p_{0, t}}
$$

The change in stator pressure ratio with stator setting angle is obtained by expressing stator pressure ratio in terms of the kinetic energy loss coefficient $\bar{e}_{30}$

$$
P R=\left[\frac{1-\bar{e}_{30}-Q_{1}}{\left(1-\bar{e}_{30}\right)\left(1-Q_{1}\right)}\right]^{r / r-1}
$$

and evaluating $\bar{e}_{30}$ from the viscous loss equation of (2)

$$
\bar{e}_{30}=\frac{\operatorname{EC}\left(\frac{\theta_{t}}{\ell}\right)_{\text {ref }}\left(\frac{\operatorname{Re}}{\operatorname{Re}{ }_{\text {ref }}}\right)^{-0.2}\left(\frac{\ell}{s}\right)\left(\frac{A_{30}}{A_{20}}\right)}{\cos a_{1}-\frac{t}{s}-H C\left(\frac{\theta_{t}}{\ell}\right)_{\text {ref }}\left(\frac{\operatorname{Re}}{\operatorname{Re}_{\text {ref }}}\right)^{-0.2}\left(\frac{l}{s}\right)}
$$

where 


$$
\begin{aligned}
& E=\frac{2\left(\frac{1}{1.92}+\frac{Q}{3.2}+\frac{Q^{2}}{4.8}+\frac{Q^{3}}{6.72}\right)}{\frac{1}{1.68}+\frac{Q}{2.88}+\frac{Q^{2}}{4.4}+\frac{Q^{3}}{6.24}} \\
& H=\frac{\frac{1}{1.2}+\frac{3 Q}{1.6}+\frac{5 Q^{2}}{2.0}+\frac{7 Q^{3}}{2.4}+\frac{9 Q^{4}}{2.8}}{\frac{1}{Q^{3}} \cdot \frac{Q}{1.68}+\frac{Q}{2.88}+\frac{Q^{2}}{4.4}+\frac{Q^{3}}{6.24}} \\
& Q=\left(\frac{r-1}{1+1}\right)\left(\frac{v}{V_{c r}}\right)^{2} \\
& \left(\frac{\theta t}{e \operatorname{Re}^{-0.2}}\right)_{\text {ref }}=0.03734
\end{aligned}
$$

Clearance flow - In the absence of experimental data a clearonce flow model is proposed to account for stator end-clearance leakage effects. The clearance flow region is defined as that region extending from the ends of the stator vanes to the passage endwalls (hub and/or tip). It is the area unblocked by vanes, extending over the clearance height, $c$. This clearance flow model, which predicts effects on performance similar to those found in (3) for an axial turbine with pivoted stator vanes, is based on the following assumptions:

(1) The clearance flow expands to the same stator-exit static pressure as the vane passage flow.

(2) The clearance flow has the same total pressure loss as the vane passage flow.

(3) Stator inlet moment of tangential momentum is conserved in the clearance flow.

From these assumptions, the lelocities and densities must be the same for both the passage and clearance flows, but the flow angles will ciffar. The clearance-flow exit angle is determined from conservation of moment of tangential momentum.

$$
a_{1, c}=\sin ^{-1}\left[\frac{\left(r v_{u}\right)_{0}}{\left(r v_{1}\right.}\right]
$$

Meitner

Thus, the clearance flow rate is

$$
w_{c}=2 \pi r_{1} c_{p_{1}} v_{1} \cos a_{1, c}
$$

Mixing - The assumed mixing process that takes place between stations 1 and 2 includes the mixing of the passage and 
ciearance flows, as well as the expansion of the mixed flow as it fills the space behirid the vane trailing edges. The expansion behind the trailing edges takes place even with no clearance flow. Mixing is assumeo to occur at constant static pressure with tangent ia? momentum being conserved.

For the mixing process, the total flow

is the sum of the passage and clearance flows

$$
w=w_{p}+w_{c}
$$

Conservation of tangential momentum between stations 1 and 2 yields

$v_{u, 2}=\frac{v_{1}}{w}\left(w_{p} \sin a_{1, p}+w_{c} \sin a_{1, c}\right)$

The cont inuity equation

$$
p_{2} v_{r, 2}=\frac{w}{2 \pi r_{2}^{h}}
$$

is solved iteratively with Eq. (12) for $V_{r}, 2$ to complete definition of the mixed f Sbw $^{2}$ at station 2. ROTOR LOSS - In the loss model of (1), the rotor loss is calculated by

$$
L_{R}=x\left(\frac{w_{3}^{2} \cos ^{2} i_{3}+w_{4}^{2}}{2}\right)
$$

The rotor loss $L_{R}$ represents all losses in the rotor except incidence loss. A variation in rotor loss coefficient $K$ with stator area change is expected because of changes in rotor reaction. That variation was obtained by using the off-design performance computer program of (1) to determine values of rotor loss coefficient that caused calculated total efficiency.+$)$ maich the data of (4).

In (4), a design rotor and two modified rotors (fig. 2), one with exducer extended to reduce rotor exit area to 53 percent of design area and one with the exducer cut back to increase rotor exit arga to 137 percent of design area, were investigated with stators having throat areas of 144, 125, $100,66,42$, and 20 percent of the design value. All stators were fixed and, thus, had no vane end-clearance leakage. Each configuration used the same vane profile, but had varying numbers of vanes and setting angles to achieve the desired flow areas. The number of vanes and angles for each configuration are shown in Table 1 . All experiments were conducted at equivalent design 
speed over a range of pressure ratios. The data for the design rotor was used to determine the variation in rotor loss coefficient $k$ with stator area. The data for the extended and cutback rotors was used to test the developed correlation.

for each stator tested with the design rotor, turbine efficiency at zero incidence angle (with respect to optimum rotor inlet flow angle) was calculated by the computer program of (1) over a ralige of rotor loss coefficients, unt il the calculated total efficiencies best matched the experimental data. The relative loss coefficients l loss coefficients divided by loss coefficient for 144 percent stator area, equal to 0.180 ) associated with the match points are shown in Fig. 3, plotted against stator-to-rotor throat area ratio, which is selected as the correlating parameter because it reflects changes in turbine reaction and can be evaluated directly from turbine geometry. The stator-to-rotor throat area ratio $A R$ is defined by

$$
A R=\frac{A_{1} \cos \alpha_{1}}{A_{4} \cos B_{4}}
$$

As seen from $F i g .3$, rotor loss coefficient remains constant for area ratios above about C.6. As area ratio decreases below 0.5 , rotor loss coefficient increases rapidly. This trend appears consistent with calculated rotor flow characteristics. Velocity calculations for the turbine hub section (4) show significant flow accelerations across the rotor for stator areas above the design yalue (AR values above approximately $0.5)$. As stator area derreases below the design value (AR values belcw approximately $0.5)$, increasing flow deceleration takes place. A more detailed description of the analytical data matching is found in (5).

INCIDENCE LOSS - In the loss model of (1), the incidence loss is expressed as

$$
L_{I N}=\frac{w_{3}^{2} \sin ^{n} i_{3}}{2}
$$

Me itner

where the exponent $n$ is 2 for negative incidence and 3 for positive incidence. The incidence angle is defined with reference to the optimum rotor-inlet flow angle.

$$
i_{3}=B_{3}-B_{3, \text { opt }}
$$


Examination of the experimental performance maps (1) used to derive the incidence loss exponents showed a very limited amount of data in the negative incldence region. The experimentai resuits being anaiyzed here in (4) provided a much better data base, both in amount of data and range of incidence angle, for modeling incidence loss. In order to obtain a concinuous variation in incidence loss with exponent $n$ at negative incidence angles, the equation for incidence loss used herein was changeo to that used in (6).

$$
L_{I N}=\frac{w_{3}^{2}\left(1-\cos ^{n} i_{3}\right)}{2}
$$

The best overall match between analysis and experiment, based on all six stators with the design rotor, was obtained with an exponent $n$ of 2.5 for negative incidence and 1.75 for positive incidence. The modified incidence loss model provided as good an analytical match of the data base ii (1) as did the original incidence mode?.

\section{LOSS MODEL EVALUATION}

In this section, calculated turbine overall perfomance using the developed loss model is compared with the experimental performance data for the design roior and the modified rotors of (4). Also, the effects of stator vane end-clearance as caiculated by the proposed loss model are presented.

DESIGN ROTOR - The experimental dat : for the design rotor with the six stato.s $(144,125,100,66,42$, and 20 percent design throat area) were used as the data base for the variation in rotor loss coefficient with stator area, as well as for the modified incidence loss model. Figures 4 and 5 show the comparisons between experimental and calculated flow and total efficiency, respectively, at constant design speed, as well as the zero incidence match points. Overall agreement between analys is and experiment is good, with the exception of the 20 percent stator area case. For the 20 percent area case, the velocity calculations

Me itner of (4) show extensive hub flow separation. which could result in the analysis not matching the trend of the efficiency data. Figure 6 shows the effect of incorporating the variation in rotor loss coefficient with stator area into the loss model. The solid lines are the design rotor total efficiency predictions using rotor losses 
obtained from Fig. 3, while the dasned lines show the predictions using the loss model of (1) (rotor loss kept constant at design point yalue;. The rotor loss variation of Fig. 3 is seen to significantly improve the total efficiency predictions.

MODIFIED ROTORS - The experimental

tests of (4) were also conducted with a cutback rotor exducer and an extended rotur exducer having throat areas equal to 137 and 53 percent, respectively, of the design rotor. The cutback rotor was tested with stators corresponding to 144,125 , and 100 percent of the design stator throat area, and the extended rotor was tested with stators corresponding to $100,66,42$, and 20 percent of the design stator throat area. The developed loss model was used to predict the results of the cutback and extended rotor tests. The loss coefficients used for the predictic were obtained from fig. 3. Figures 7 and 8 show the comparison between experimental and calculated flow and total efficiency, respectively, for the cutback and extended rotors. Agreement is generally satisfactory with regard to both level and trend. For the same reasons as discussed for the design rotor, the experimental and analytical efficiency trends for the 20 percent stator do not match as well as for the other stators. The overall agreement, however, sustantiates the valiaity of the derived correlation of rotor loss coefficient with stator-to-rotor throat area ratio.

STATOR CLEARANCE - All data of (4) were taken with fixed stators having no vane endclearance and a direct comparison between analytical and experimental results for stator end-clearance leakage is thus not possible. The described clearance flow model was used to predict turbine performance for the design rotor with various stator vane endclearances. For all calculations with stator vane end-clearance, the stator total pressure ratio $P R$ and the rotor loss coefficient $K$ were assumed to be equal to the no clearance values.

Figure 9 shows the calculated effect of stator clearance on mass flow at constant turbine pressure ratio over a range of stator area. These results are independent of turbine pressure ratio. For a given stator clearance, the mass flow ratio increases rapialy with decreasing stator area. Inis occurs because the clearance flow becomes a larger portion of the total flow as the passage are, decreases. As stator clearance

Meitney 
is increased at a fixed stator area, the mass flow increases at a rate nearly linear with clearance. Figure 10 shows the calculated effect of stator clearance on tota? efficiency at constant turbine pressure ratio over a range of stator area. These results vary only slightly with turbine pressure ratio. For a given stator clearance, the efficiency penalty due to the clearance flow becomes significantly larger as stator area decreases. This occurs primarily as a result of the greater loss in tangential momentum as clearance flow becomes a larger part of the total flow. As statcr clearance is increased at a fixed stator area, the efficiency penalcy increases at a rate nearly linear with clearance.

\section{SUMMARY}

An off-design performance loss model for a radial turoine with pivoting, variable-area stators was developed through a combination of analytical modeling and analysis of experimental data. A viscous loss model is used for the variation in stator loss with setting zingle. Stator vane end-clearance leakage effects are predicted by a clearance flow model. The variation in rotor loss coefficient with stator setting angle (for no stator clearance) is obtained by analytical matching of experimental data for a rotor previously tested (at constant speed) with six stators having throat areas from 20 to 144 percent of design area. un incidence loss model is selected to ol best agreement with experimental data. Predicted turbine performance is compared with experinental results for the design rotor as well as for versions of the rotor having extendes and cutback exducers. Sample calculations are made to show the effects of stator vane end-clearance leakage.

The six design rotor loss coefficients obtained by analysis from the experimental data yield a smooth curve when plotted against stator-to-rotor throat area ratio. For area ratio above 0.6 , rotor loss coefficient remains constant. As area ratio decreases below 0.5 , rotor loss coefficient increases rapidly. This variation in rotor loss coefficient with stator throat area is consistent with calculated rotor internal flow characteristics.

Predicted flows and total efficiencies for the design rotor, as well as for the rotor with an exterded exducer (53 percent 
of design rotor tirroat area) and a cutback exducer (137 percellt of design rotor thrcat area) agree well with experimental results, except for the 20 percent siatur area cases, where analysis indicates extensive flow separation. This good agreement substiontiates the validity of the derived correiation of rotor loss coefficient with statorto-rotor throat area ratio.

The stator vane end-clearance leakage model predicts increasing mass flow and decreasing efficiency as a result of endclearances. These changes become significantly larger with decreasing stator area and vary almost linearly with clearance.

\section{REFERENCES}

1. C. A. Wasserbauer and A. J. Glassman, "FCRTR.AN P!ugram for Predicting Off-Design Performance of Radial-Inflow Turbines," NASA TN i-8063, 1975.

2. A. J. Glassman, "Computer Program for Design Analysis of Radial-Inflow Turbines," NASA TN D-8164, 1976.

3. M. G. Kofskey and K. L. McLallin, "Cold Air Performance of Free Power Turbine Designed for 112-Kilowatt Automotive GasTurbine Engine, 3: Effect of Stator Vane End Clearances on Perfurmance." DOE/NASA/1011-78/29, NASA TH-78956, 1978.

4. M. G. Kotiskey and W. J. Nusbaum, "Effects of Specific Speed on Experimental Performance cf a Radial-Inflow Turbine," NASA TN $0 .-6605,1972$.

5. P. L. Meitner and A. 1. Glassman, "Off-Design Performance Loss Model for Radia) Turbines with Pivoting Variable-Area Stators." NASA TP-1708, 1980.

6. R. J. Roelke, "Miscel'aneous Losses. "Turbine Design and Application, A. J. Glassman, ed., NASA SP-290, Vol. 2, 1973, pp. 125-148. 
Table 1. - Sumnary of Geometric Data for Design. Extended and C . Back Rotors

Design Rotor Configurations

\begin{tabular}{|c|c|c|c|}
\hline $\begin{array}{l}\text { Stator } \\
\text { throat } \\
\text { area } \\
\text { (percent } \\
\text { design) }\end{array}$ & $\begin{array}{l}\text { No. of } \\
\text { stator } \\
\text { vanes }\end{array}$ & $\begin{array}{c}\text { Stator exit } \\
\text { flow angle- } \\
\text { al, } \\
\text { deg }\end{array}$ & $\begin{array}{l}\text { Rotor exit } \\
\text { flow angle- } \\
\text { Bu, } \\
\text { deg }\end{array}$ \\
\hline $\begin{array}{r}144 \\
125 \\
100 \\
66 \\
42 \\
20\end{array}$ & $\begin{array}{l}13 \\
13 \\
13 \\
15 \\
17 \\
17\end{array}$ & $\begin{array}{l}64.70 \\
68.00 \\
72.47 \\
77.75 \\
81.38 \\
85.00\end{array}$ & -56.86 \\
\hline
\end{tabular}

Extended Rotor Configurations

\begin{tabular}{|c|c|c|c|}
\hline $\begin{array}{c}\text { Stator } \\
\text { throat } \\
\text { area } \\
\text { (percent } \\
\text { design) } \\
\end{array}$ & $\begin{array}{l}\text { No. of } \\
\text { stator } \\
\text { vanes }\end{array}$ & $\begin{array}{l}\text { Stator exit } \\
\text { flow angle- } \\
\text { al, } \\
\text { Jeg }\end{array}$ & $\begin{array}{l}\text { Rotor exit } \\
\text { flow angle- } \\
\text { B4, } \\
\text { deg }\end{array}$ \\
\hline $\begin{array}{r}100 \\
66 \\
42 \\
20\end{array}$ & $\begin{array}{l}13 \\
15 \\
17 \\
17\end{array}$ & $\begin{array}{l}72.47 \\
77.75 \\
81.38 \\
85.00\end{array}$ & -72.56 \\
\hline
\end{tabular}

Cut-Back Rotor Configurations

\begin{tabular}{|c|c|c|c|c|}
\hline $\begin{array}{l}\text { Stator } \\
\text { throat } \\
\text { area } \\
\text { (percent } \\
\text { design) } \\
\end{array}$ & $\begin{array}{l}\text { No. of } \\
\text { stator } \\
\text { vanes }\end{array}$ & $\begin{array}{l}\text { Stator exit } \\
\text { flow angle- } \\
\text { al, } \\
\text { deg }\end{array}$ & $\begin{array}{l}\text { Rotor exit } \\
\text { flow angle- } \\
\text { B4, } \\
\text { deg }\end{array}$ & Meitner \\
\hline $\begin{array}{l}144 \\
125 \\
100\end{array}$ & $\begin{array}{l}13 \\
13 \\
13\end{array}$ & $\begin{array}{l}64.70 \\
68.00 \\
72.47\end{array}$ & -42.07 & 12 \\
\hline
\end{tabular}




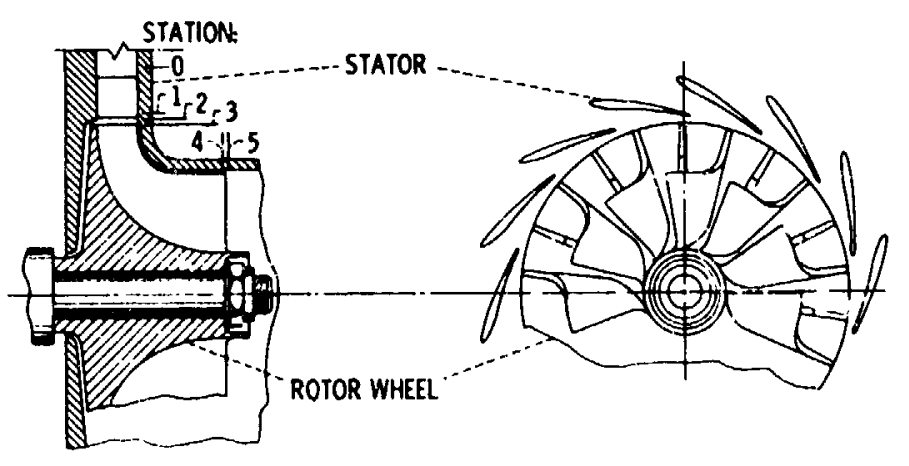

Figure 1. - Crnss section of radial turbine.

CD-1185?-DQ 


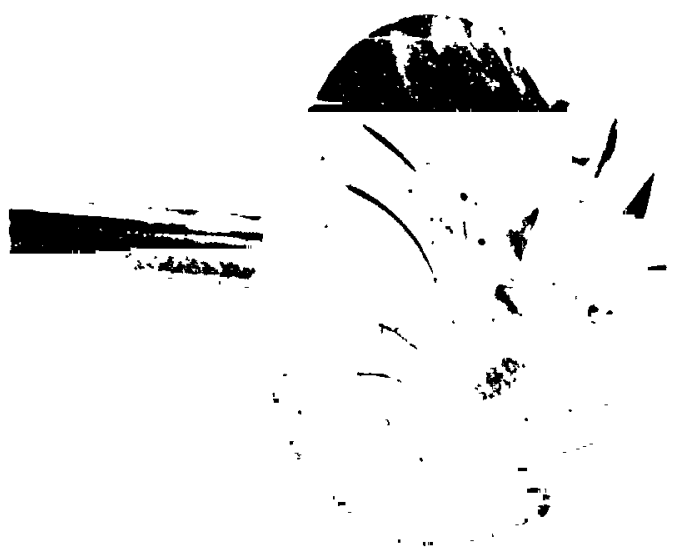

$C-71-759$

(d) DESIGN ROTOR.

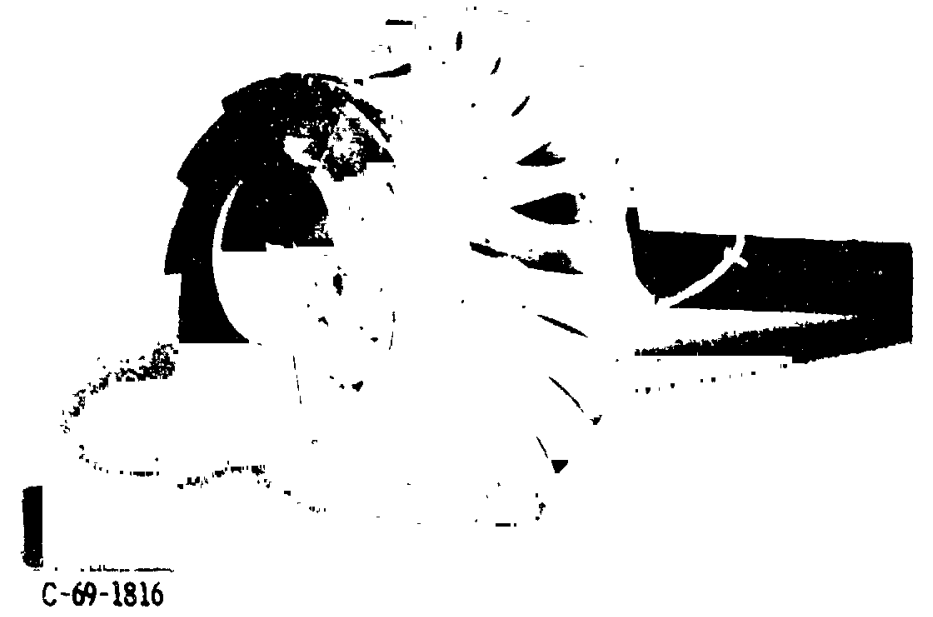

(b) ROTOR IVITHA XDUCER IXIENSION.

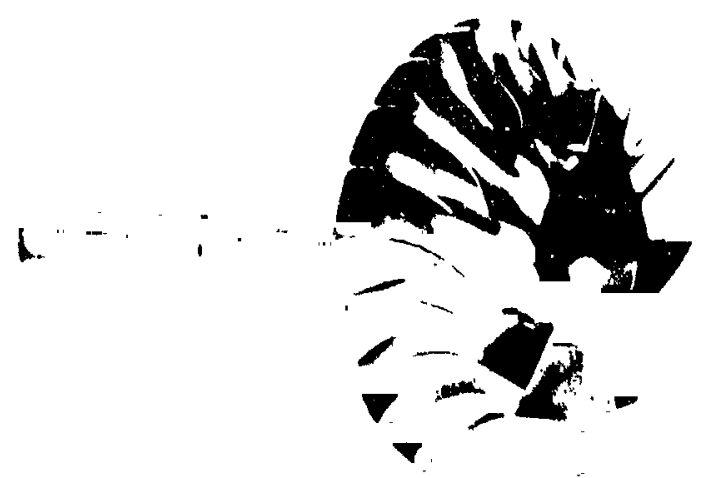

C- $-70-3533$

(c) CUTBACK ROTOR.

Irque 2. Rotor contegurations. 

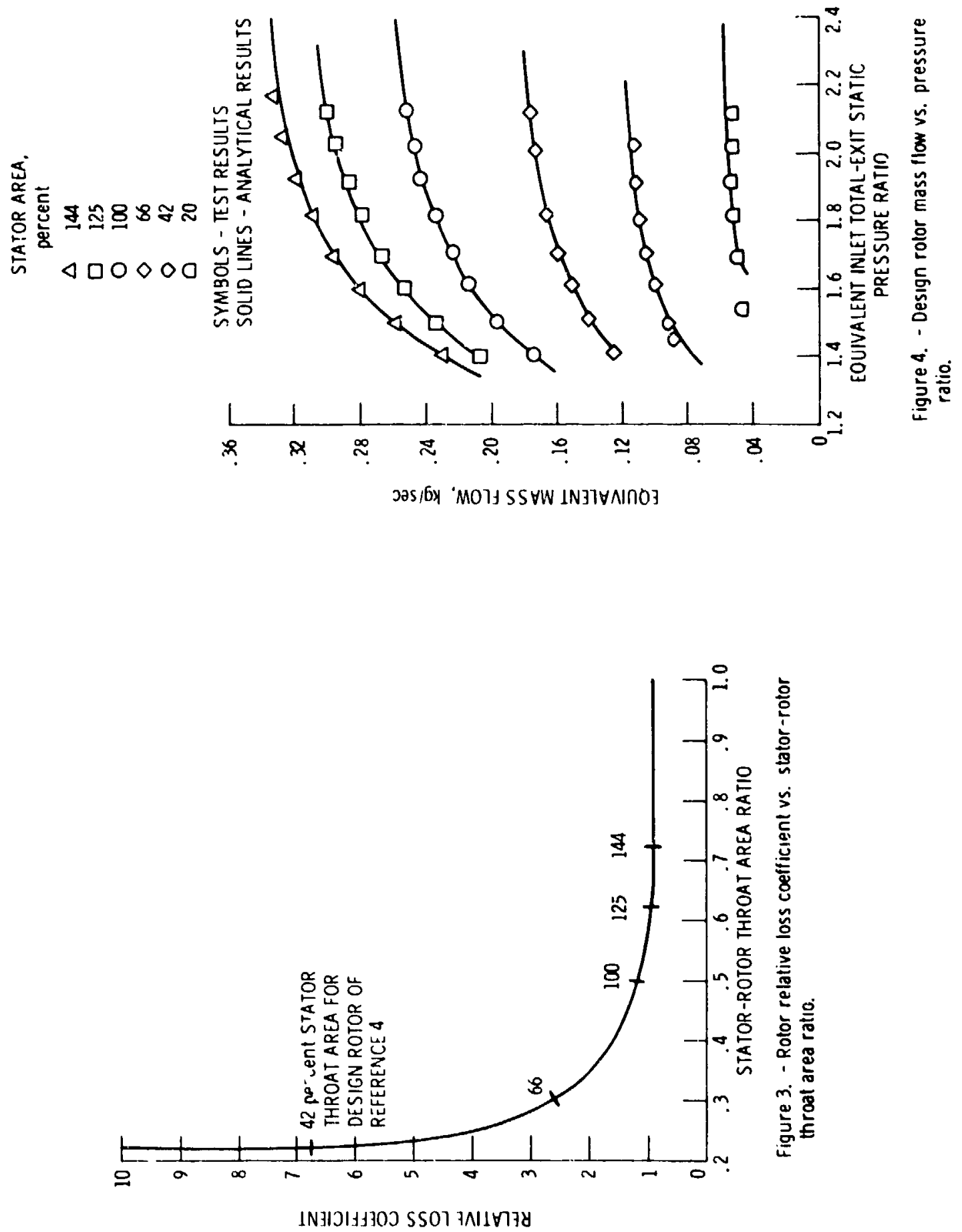

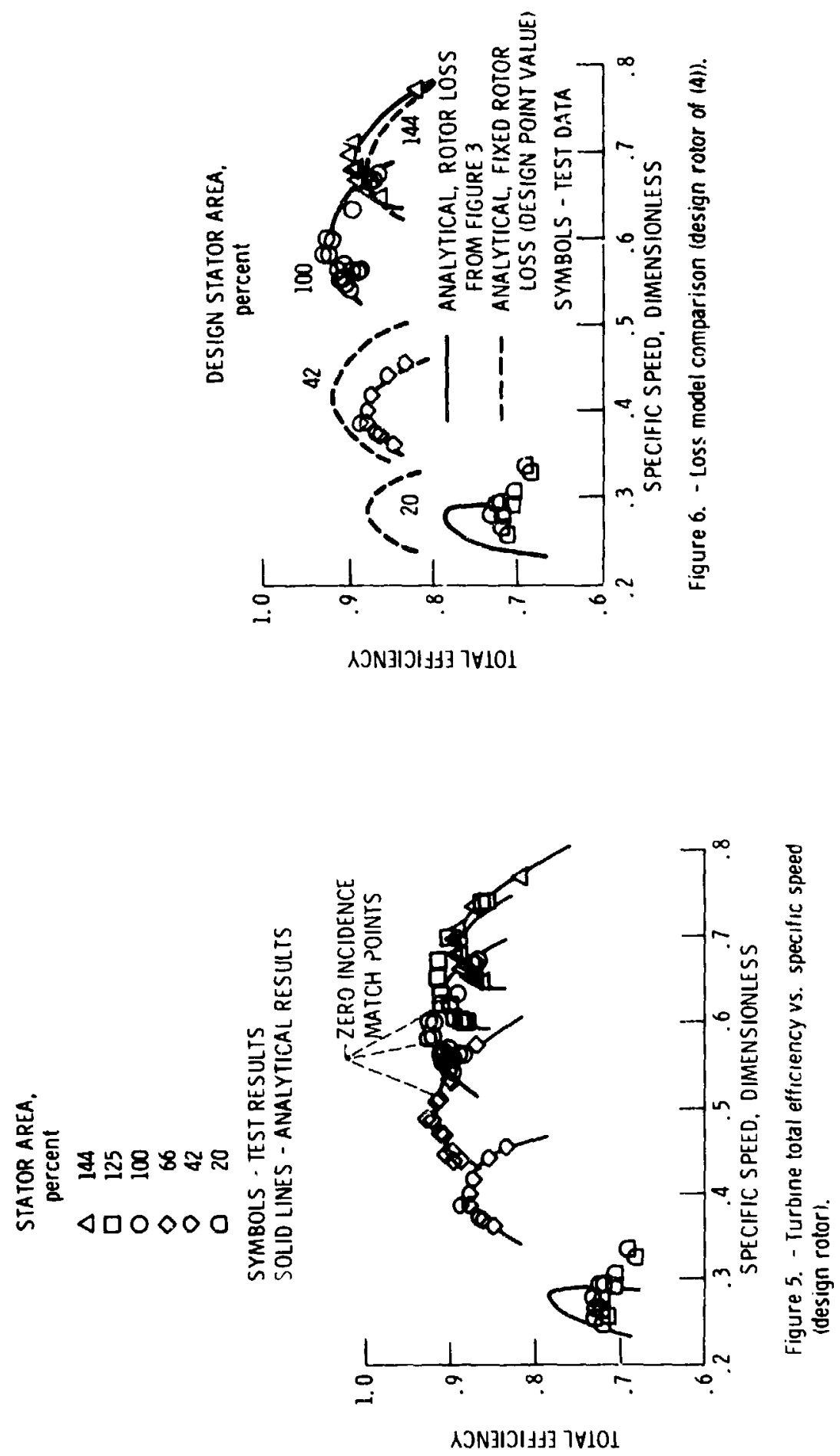


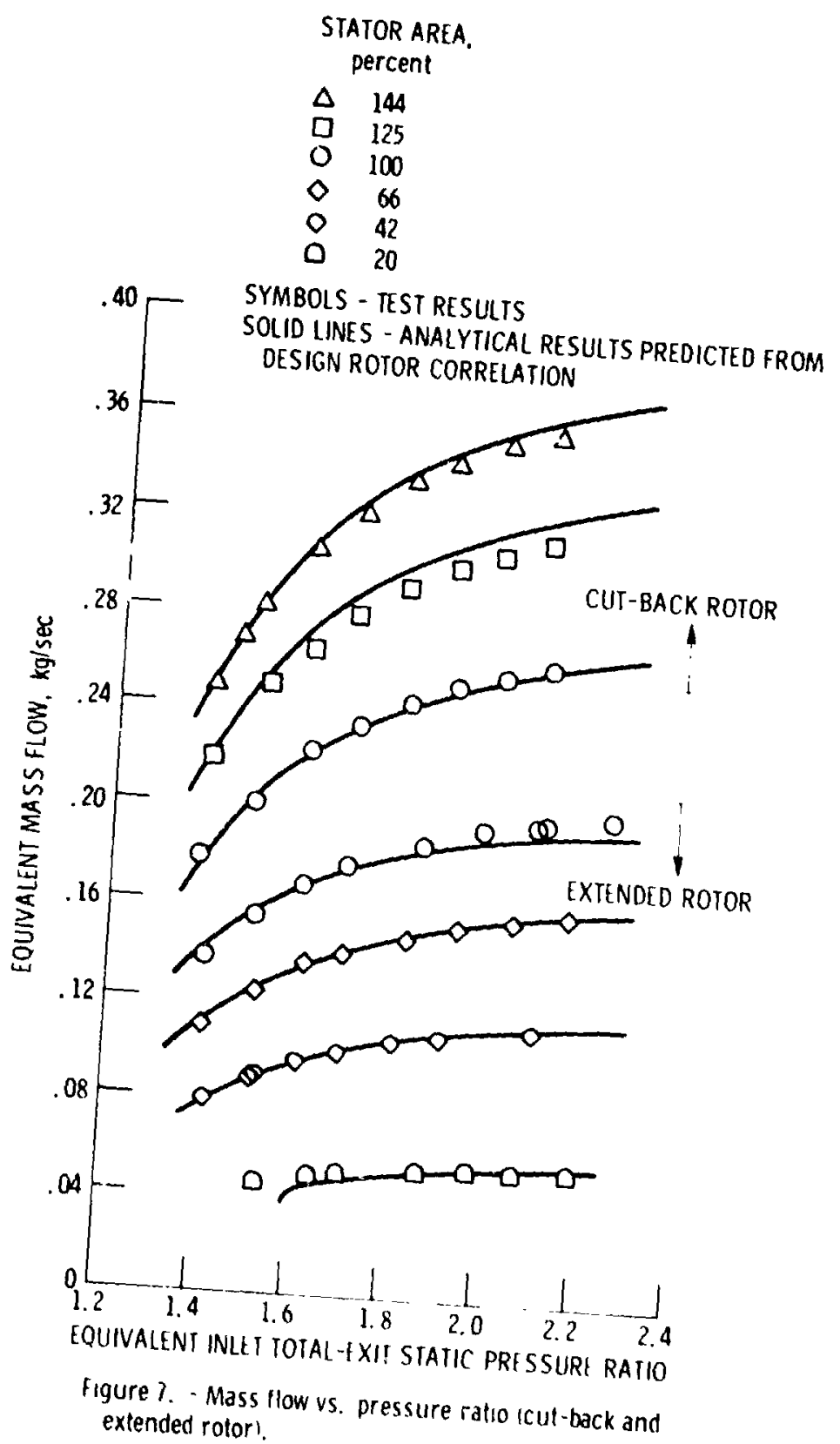



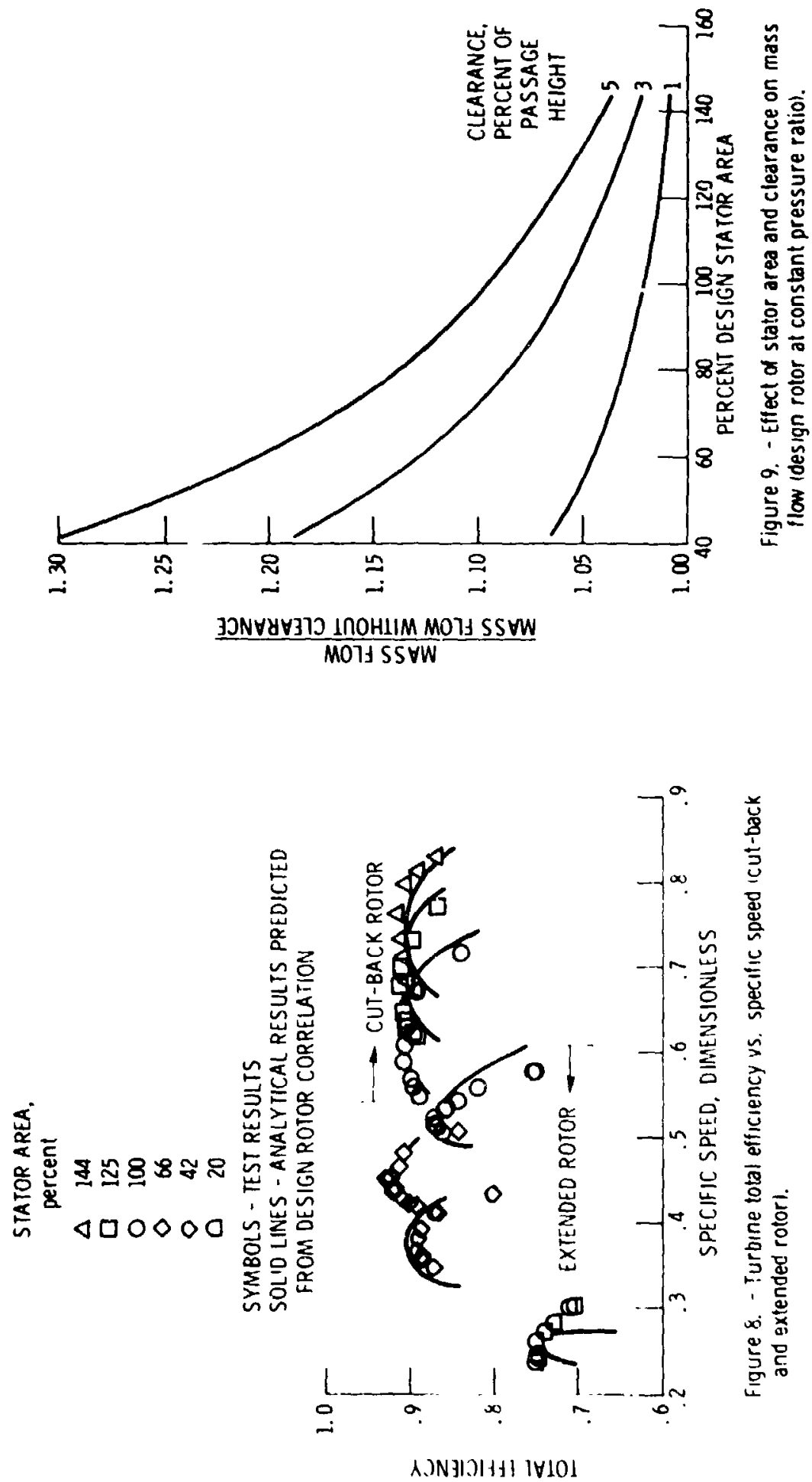


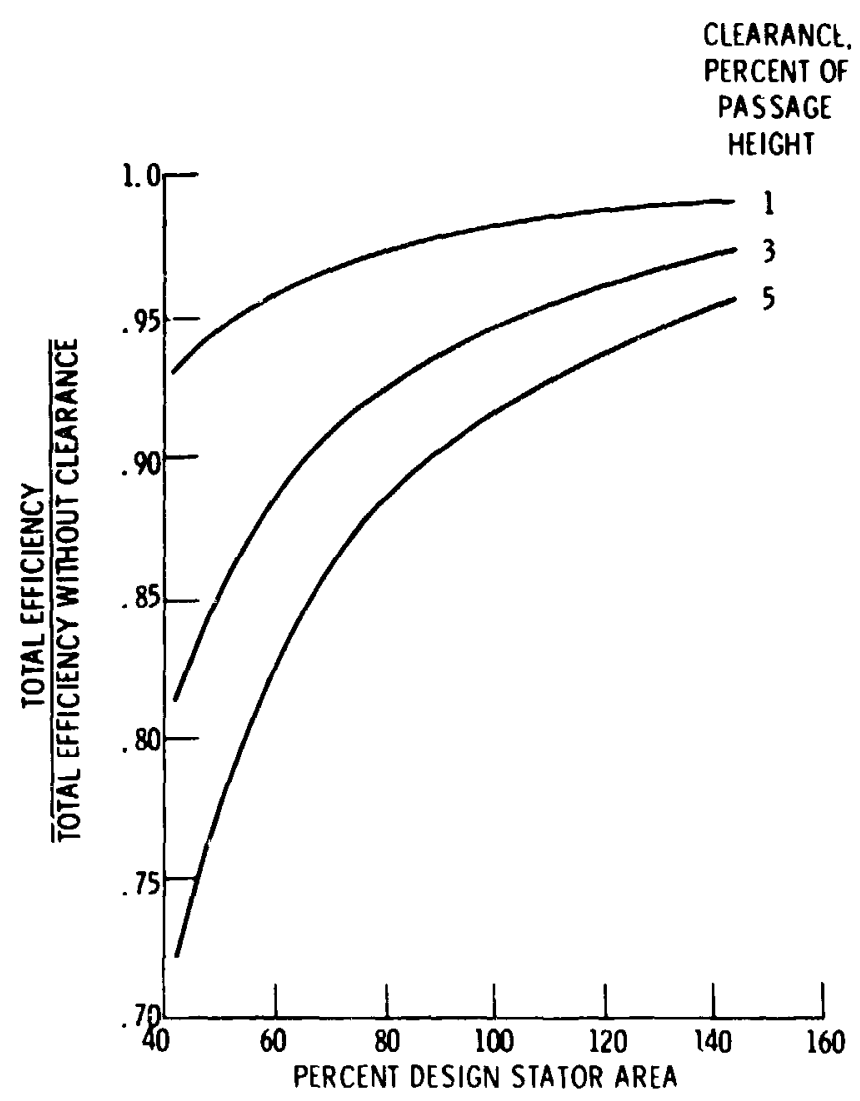

Figure 10. - Effect of stator area and clearance on total efficiency (design rotor at constant pressure ratio). 